\title{
IMMUNOHISTOCHEMICAL CHARACTERISATION OF LYMPHOID POPULATIONS IN RABBIT JEJUNAL PEYER'S PATCH
}

\author{
Volodymyr Khomych \\ Academician Volodymyr Kasyanenko Department of \\ Animal Anatomy, Histology and Pathomorphology ${ }^{1}$ \\ gistology_chair@nubip.edu.ua \\ Olha Fedorenko \\ Academician Volodymyr Kasyanenko Department of \\ Animal Anatomy, Histology and Pathomorphology ${ }^{1}$ \\ olhafedorenko@ukr.net
}

${ }^{1}$ National University of Life and Environmental Sciences of Ukraine

15 Heroyiv Oborony str., Kyiv, Ukraine, 03041

\begin{abstract}
Rabbits are an important livestock animal species, which are used for their meat and fur. Nowadays they are also becoming more popular as pets. Furthermore, rabbits are commonly used in research, inter alia in immunological studies and for studying pathogenesis of human and animal diseases.

The lymphoid tissue is abundant in the rabbit intestine and a lot of it is concentrated in Peyer's patches, the majority of which is located in the jejunum. Understanding of the rabbit Peyer's patches functions is essential for the prevention and treatment of their diseases. In order to enhance it, accurate knowledge of its lymphocyte population composition is needed. At present, the cellular composition of the rabbit gut-associated lymphoid tissue remains insufficiently studied. Therefore, the aim of our study was to establish the content and localization of lymphoid populations in the domestic rabbit jejunal Peyer's patches.

We performed immunohistochemical studies using monoclonal antibodies CD3, CD10 and CD20 (DAKO, Denmark) to identify the distribution of lymphoid populations in jejunal Peyer's patches of a mature domestic rabbit. The results, obtained in our study, complement the existing data and determine the main lymphoid populations in the rabbit jejunal Peyer's patches. The presented data are fundamental for further studies of the rabbit gut-associated lymphoid tissue.

We found that lymphoid nodules of jejunal Peyer's patches contains a predominant $\mathrm{CD} 20^{+}$cell population (B cells). It also contains many $\mathrm{CD} 10^{+}$cells (precursors of $\mathrm{T}$ cells and $\mathrm{B}$ cells), which are mostly concentrated in the germinal centers of lymphoid nodules. In the diffuse form of the lymphoid tissue the vast majority of cells are $\mathrm{CD}^{+}$cells (T cells).
\end{abstract}

Keywords: rabbit, jejunum, lymphoid tissue, Peyer's patch, CD3, CD10, CD20, immunohistochemistry.

DOI: $10.21303 / 2504-5695.2020 .001402$

\section{Introduction}

Rabbits are actively used as livestock due to their high quality meat, valuable fur, fertility and precocity, relatively low feed costs and simple housing requirements [1]. Nowadays they are also becoming more popular as pets. Moreover, rabbits are considered useful animal models in studying pathogenesis of human and animal diseases, including those, whose pathogens enter the body through the digestive system [2-4]. Rabbits are also used in immunology for production of polyclonal antibodies [5].

The lymphoid tissue is abundant in the rabbit intestine and a lot of it is concentrated in Peyer's patches, the majority of which is located in the jejunum [3,6]. Peyer's patches belong to the peripheral organs of hemo- and lymphopoiesis. They are among the first to respond to antigens that enter the body with feed and water. As a consequence, their lymphocytes transform into effector cells, which determine immunity. They also inform the body about the nature of the antigen that has entered it.

Understanding of the rabbit Peyer's patches functions is essential for the prevention and treatment of their diseases. In order to enhance it, accurate knowledge of its lymphocyte population composition is needed [7-10]. Therefore, the aim of our study was to establish the content and localization of lymphoid populations in the domestic rabbit jejunal Peyer's patches. 


\section{Materials and methods}

The study was conducted over the period from 2016 to 2020. For immunohistochemical studies four clinically healthy four-months-old male Pannon White rabbits were used. The animals were kept in accordance with generally accepted husbandry practices in the vivarium of the National University of Life and Environmental Sciences of Ukraine. The animals were euthanized for sample collection in the laboratory of immunomorphology of the Volodymyr Kasianenko Department of Animal Anatomy, Histology and Pathomorphology of the National University of Life and Environmental Sciences of Ukraine. All manipulations and euthanasia were carried out in concordance with norms of bioethics and in compliance with the requirements of the European Convention for the Protection of Vertebrate Animals used for Experimental and Other Scientific Purposes (Strasbourg, 1986) and the resolution of the First National Congress on Bioethics (Kyiv, 2001).

Immunohistochemical studies were performed using monoclonal antibodies CD3, CD10 and CD20 (DAKO, Denmark). Unmasking of antigens was performed via heat-induced epitope retrieval using Target Retrieval Solution High pH buffer (DAKO, Denmark) in Pt Module (Dako, Denmark) for $32 \mathrm{~min}$ at a temperature of $98-99^{\circ} \mathrm{C}$. For visualization of primary antibodies DAKO EnVision FLEX+ detection system was used. The preparations were additionally stained with Mayer's hematoxylin for 1-3 min and placed in Eukitt mounting medium. For establishing content and localization of lymphoid populations the tissue sections were examined using an "Olympus" microscope $(\times 200, \times 400, \times 1000)$. The number of lymphocytes, expressing markers, was counted on 10 randomly selected fields of microscope (per conventional unit area at magnification $\times 280$ ). Results are expressed as mean (M) and standard error of the mean (m).

\section{Results}

Previously we studied the cellular composition of a rabbit jejunal Peyer's patch [11]. The vast majority of it is represented by lymphocytes. We used markers CD3, CD10 and CD20 to determine the location and quantitative indicators of their cell populations.

In the rabbit jejunal Peyer's patch a reaction to the presence of these cellular markers was positive. The content of cell populations, expressing markers CD3, CD20 and CD10, differed in nodular and diffuse forms of the lymphoid tissue (Table 1).

Table 1

The content of lymphocyte populations in rabbit jejunal Peyer's patch (cells per conventional unit area), $\mathrm{M} \pm \mathrm{m}$

\begin{tabular}{cccc}
\hline Marker & Germinal center of lymphoid nodule & Dome of lymphoid nodule & Diffuse lymphoid tissue \\
\hline CD3 & $21.3 \pm 2.13$ & $48.5 \pm 4.88$ & $113.3 \pm 3.68$ \\
CD10 & $98.7 \pm 1.36$ & $43.7 \pm 3.1$ & $42.0 \pm 5.23$ \\
CD20 & $107.7 \pm 4.84$ & $91.3 \pm 3.08$ & $38.5 \pm 1.99$
\end{tabular}

Anti-CD3 monoclonal antibodies are used as T cell markers. They express this marker on a cell membrane, which gives the cell a characteristic brown annular appearance. In the jejunal Peyer's patch T cells are mostly localized in the diffuse lymphoid tissue between the lymphoid nodules, where their cell population makes up the vast majority and occupies almost this entire area.

A smaller number of $\mathrm{T}$ cells is found in the domes of lymphoid nodules, where they are located more diffusely. Here their content is 2.3 times, i. e. $57.2 \%$ lower than in the diffuse lymphoid tissue.

The least amount of $\mathrm{T}$ cells is located in the germinal center of the lymphoid nodule. They are mostly located on their periphery, but sometimes found in their central zone. In the germinal centers of secondary lymphoid nodules the content of these lymphocytes is 5.3 times lower $(81.18 \%)$ than in the diffuse lymphoid tissue. It's also 2.3 times $(56.02 \%)$ lower than in the dome region. In primary lymphoid nodules we found only single $\mathrm{CD}^{+}$lymphocytes, which were randomly arranged over their entire area. 
T cells are also diffusely located in the connective tissue of lamina propria within the mucosa. They can be found between crypts, in intestinal villi and in the submucosa. $\mathrm{CD}^{+}$lymphocytes are also present in the follicle-associated epithelium.

Anti-CD20 monoclonal antibodies are expressed by B cells. According to our observations, this population of lymphocytes is the largest in the jejunal Peyer's patch. Most of them are very densely located in the germinal centers of lymphoid nodules. In the mantle zone of secondary lymphoid nodules the concentration of B cells was lower and they had a lower level of expression of this immunohistochemical marker compared to $\mathrm{CD} 20^{+}$cells of the germinal center.

$\mathrm{B}$ cells are less densely located in the domes of lymphoid nodules compared to germinal centers. In the dome region their number is 1.2 times and, accordingly, $15.25 \%$ lower than in the germinal centers of lymphoid nodules.

B cells sometimes are found in the capsule of lymphoid nodules. They are also located in the diffuse lymphoid tissue as single cells or small clusters but their number is much lower compared to the germinal centers: 2.8 times, i. e. $64.24 \%$; and 2.4 times (57.81\%) lower than in the dome region.

$\mathrm{B}$ cells are found in intestinal villi, they also infiltrate the superficial and follicle-associated epithelium.

Anti-CD10 monoclonal antibodies are expressed by precursors of T cells and B cells. They are mostly concentrated in the germinal centers of lymphoid nodules, where they occupy their whole area. In the mantle zone of the lymph nodules $\mathrm{CD} 10^{+}$cells are less densely located. In the domes of lymph nodules $\mathrm{CD} 10^{+}$cells are located less densely and have a lower degree of expression compared to cells in the germinal centers. Their number is 2.3 times, i. e. $55.74 \%$ lower than in the germinal centers of lymphoid nodules.

In the diffuse lymphoid tissue $\mathrm{CD} 10^{+}$cells are less common. Here their number is 2.3 times lower than in the germinal centers (i. e. $57.43 \%$ ) and $3.82 \%$ lower than in the domes of lymphoid nodules. The number and density of $\mathrm{CD} 10^{+}$cells in the diffuse lymphoid tissue increase closer to the mucosal surface epithelium, as does the level of expression of this marker.

In the intestinal villi and between the crypts of the mucous membrane $\mathrm{CD} 10^{+}$cells are spread out or grouped in small clusters.

The cytoplasm of intestinal epithelial cells shows the moderate intensity immunostaining with CD10 marker. CD10 emphasizes the intestinal brush border of the superficial epithelium [12], which on histopreparations has an appearance of a clear dark stripe or of a dark circle inside the crypt in their cross section.

CD10 is also expressed by cells that surround lymph nodules with domes only below and at the sides. Judging by their characteristic elongated shape, these cells may be fibroblasts (Fig. 1).

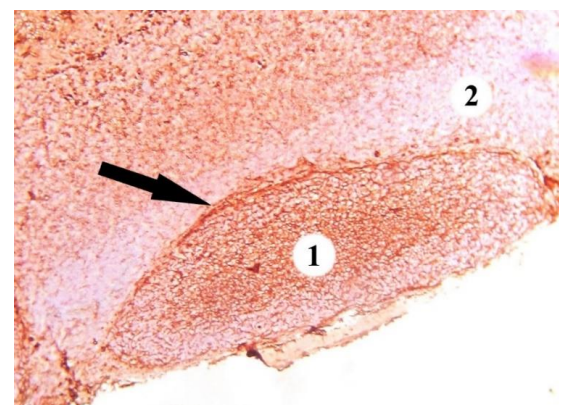

Fig. 1. Expression of CD10 by cells along the perimeter of the lymphoid nodule (arrow):

$1-\mathrm{CD} 10^{+}$cells in the germinal center of the lymphoid nodule; 2 - diffuse lymphoid tissue.

Histopreparation with the use of monoclonal antibodies, $\times 100$

\section{Discussion}

Immunohistochemistry allows to detect the localization of certain antigens in cells, based on the specific binding of antigens to antibodies. It enables the visualization of antigens in histopreparations with preservation of the tissue microarchitecture. 
Although the antibodies we used have been developed against the corresponding human antigens, it is known, that some antigens are common across many species, such as CD3. Human markers are quite effective in studies on mice [13]. In other sources it is noted, that rabbit B cells, as well as in humans, express markers CD10 and CD20 [14]. The positive specific reaction with the antibodies we used was confirmed by characteristic membranous pattern of staining.

Currently most information about the adaptive immune system comes from studies on peripheral blood, which contains only $2 \%$ of body lymphocytes [15]. At the same time the gut-associated lymphoid tissue has a special role in the development of B cells in many species (sheep, cattle, rabbits and pigs) $[16,17]$. On the basis of the aforesaid, studies of the lymphoid populations in the rabbit jejunal Peyer's patch are relevant.

It is known, that CD3 is a multidomain component of the T-cell receptor complex, which is usually located in the cytoplasm of immature T-lymphoblasts and on the surface membrane of mature T cells. It has a complex structure and contains three different polypeptide dimers. NK cells may also have cytoplasmic expression of CD3. Nonspecific cytoplasmic staining of plasma cells and macrophages is also possible [18].

CD10 is a neutral endopeptidase, also known as a common acute lymphoblastic leukemia antigen (CALLA). It is expressed on the early precursors of T cells and B cells, disappears as they mature, and reappears on activated B cells. This molecule may also be present on granulocytes, fibroblasts, follicular dendritic cells and some epithelial cells [18, 19].

CD20 is one of the main markers, used to identify B cells. It is a surface membrane molecule that plays a role in the proliferation and differentiation of B cells into plasma cells. It appears in the ontogeny of B cells somewhat later than CD10 expression. CD20 is expressed on B cells during their differentiation before their transformation into plasma cells. Expression by follicular dendritic cells is also possible [18-20].

$\mathrm{B}$ cells are a key component of the adaptive immune response. Although their main function is to produce antibodies, they can also act as antigen-presenting cells or regulatory cells, producing cytokines that affect the inflammatory response [21].

It is known, that in neonatal rabbits $\mathrm{CD} 20^{+} \mathrm{B}$ cells first appear in the domes, mucosal folds and intestinal villi. Differentiation into B cells of germinal centers occurs later. During their development B cells at first migrate to the appendix and sacculus rotundus, and only then to other tissues (Peyer's patches, mesenteric lymph nodes, peripheral blood) [14].

The results, obtained in our study, complement the existing data and determine the main lymphoid populations in the rabbit jejunal Peyer's patches. The data, presented in this paper, are fundamental for further studies of the rabbit gut-associated lymphoid tissue.

\section{Conclusion}

1. Immunohistochemical studies of rabbit jejunal Peyer's patches revealed lymphoid populations that express markers CD3, CD10 and CD20.

2. $\mathrm{CD} 20^{+}$cells (B cells) are mostly located in the nodular form of the lymphoid tissue. It also contains many $\mathrm{CD} 10^{+}$cells (precursors of $\mathrm{T}$ cells and B cells), which are mostly concentrated in the germinal centers of lymphoid nodules. In the diffuse form of the lymphoid tissue the vast majority of cells are $\mathrm{CD}^{+}$cells (T cells).

\section{References}

[1] Gavrilin, P. M., Nikitina, M. O. (2019). Microanatomical aspects of the intestines and gut-associated lymphoid tissue of meat rabbits. Theoretical and Applied Veterinary Medicine, 7 (1), 42-46. doi: https://doi.org/10.32819/2019.71008

[2] Mage, R. G., Pinheiro, A., Lemos de Matos, A., Esteves, P. J. (2016). The Immune System of Lagomorphs. Encyclopedia of Immunobiology, 515-525. doi: https://doi.org/10.1016/b978-0-12-374279-7.12016-8

[3] Urbiztondo, R. (2010). Studies of gut-associated lymphoid tissues and other secondary lymphoid tissues in 12 week old New Zealand White specific pathogen free rabbits. (Master's thesis). The Ohio State University, Columbus, Ohio, United States. Available at: https://etd.ohiolink.edu/!etd.send_file?accession=osu1282085851\&disposition=inline 
[4] Esteves, P. J., Abrantes, J., Baldauf, H.-M., BenMohamed, L., Chen, Y., Christensen, N. et. al. (2018). The wide utility of rabbits as models of human diseases. Experimental \& Molecular Medicine, 50 (5), 1-10. doi: https://doi.org/10.1038/s12276-018-0094-1

[5] Pinheiro, A., Neves, F., Lemos de Matos, A., Abrantes, J., van der Loo, W., Mage, R., Esteves, P. J. (2015). An overview of the lagomorph immune system and its genetic diversity. Immunogenetics, 68 (2), 83-107. doi: https://doi.org/10.1007/s00251-0150868-8

[6] Ranjan, R., Das, P., Minj, A. P. (2016). Histomorphological Studies on the Gut-associated Lymphatic Tissues (GALT) in Rabbit. Indian Journal of Veterinary Anatomy, 28 (2), 51-53. Available at: https://www.researchgate.net/publication/315893902 Histomorphological_studies_on_the_Gut-associated_Lymphatic_tissues_GALT_in_Rabbit

[7] Shubina, T. P., Choporova, N. V. (2015). Comparative characteristics of the digestive organs of fur-bearing animals. Scientific-methodical electronic journal "Concept" 13 (3), 4076-4080. Available at: https://e-koncept.ru/2015/85816.htm

[8] Maroilley, T., Berri, M., Lemonnier, G., Esquerré, D., Chevaleyre, C., Mélo, S. et. al. (2018). Immunome differences between porcine ileal and jejunal Peyer's patches revealed by global transcriptome sequencing of gut-associated lymphoid tissues. Scientific Reports, 8 (1). doi: https://doi.org/10.1038/s41598-018-27019-7

[9] Haines, R. A., Urbiztondo, R. A., Haynes, R. A. H., Simpson, E., Niewiesk, S., Lairmore, M. D. (2016). Characterization of New Zealand White Rabbit Gut-Associated Lymphoid Tissues and Use as Viral Oncology Animal Model. ILAR Journal, 57 (1), 34-43. doi: https://doi.org/10.1093/ilar/ilw004

[10] Ericsson, A. C. (2019). The use of non-rodent model species in microbiota studies. Laboratory Animals, 53 (3), $259-270$. doi: https://doi.org/10.1177/0023677219834593

[11] Khomych, V. T., Fedorenko, O. V. (2019). The cellular composition of rabbit jejunal Peyer's patches. Actual Aspects of Animal Biology, Veterinary Medicine And Veterinary - Sanitary Examination. IV International Scientific and Practical Conference of Teachers and Students. Dnipro, 134-135. Available at: http://biosafety-center.com/wp-content/uploads/2019/06/\%D0\% BF\%D0\%B5\%D1\%80\%D0\%B5\%D0\%B3\%D0\%BB\%D1\%8F\%D0\%BD\%D1\%83\%D1\%82\%D0\%B8-\%D0\%B2-PDF1.pdf

[12] Lloyd, J. M., Owens, S. R. (2011). CD10 immunohistochemistry stains enteric mucosa, but negative staining is unreliable in the setting of active enteritis. Modern Pathology, 24 (12), 1627-1632. doi: https://oi.org/10.1038/modpathol.2011.122

[13] Rehg, J. E., Bush, D., Ward, J. M. (2012). The Utility of Immunohistochemistry for the Identification of Hematopoietic and Lymphoid Cells in Normal Tissues and Interpretation of Proliferative and Inflammatory Lesions of Mice and Rats. Toxicologic Pathology, 40 (2), 345-374. doi: https://doi.org/10.1177/0192623311430695

[14] Yeramilli, V. A. (2010). B Lymphocyte Development in GALT. (Dissertation). Loyola University Chicago, Chicago, Illinois, United States. Available at: https://www.researchgate.net/publication/254615532_B_Lymphocyte_Development_in_Galt

[15] Dock, J., Ramirez, C. M., Hultin, L., Hausner, M. A., Hultin, P., Elliott, J. et. al. (2017). Distinct aging profiles of CD8 $8^{+}$T cells in blood versus gastrointestinal mucosal compartments. PLOS ONE, 12 (8), e0182498. doi: https://doi.org/10.1371/journal. pone. 0182498

[16] Alitheen, N. B., McClure, S., McCullagh, P. (2010). B-cell development: one problem, multiple solutions. Immunology \& Cell Biology, 88 (4), 445-450. doi: https://doi.org/10.1038/icb.2009.119

[17] Meštanová, V., Varga, I. (2016). Morphological view on the evolution of the immunity and lymphoid organs of vertebrates, focused on thymus. Biologia, 71 (10). doi: https://doi.org/10.1515/biolog-2016-0137

[18] Naeim, F., Nagesh Rao, P., Song, S. X., Phan, R. T. (2018). Principles of Immunophenotyping. Atlas of Hematopathology, 29-56. doi: https://doi.org/10.1016/b978-0-12-809843-1.00002-4

[19] Delves, P. J., Martin, S., Burton, D. R., Roitt, I. M. (2011). Roitt's Essential Immunology. Wiley-Blackwell, 560.

[20] Murphy, K., Weaver, C. (2017). Janeway’s Immunobiology. Garland Science, Taylor \& Francis Group, LLC.

[21] Mitroi, M., Albulescu, D., Capitanescu, A., Docea, A., Musat, G., Mitroi, G. et. al. (2019). Differences in the distribution of CD20, CD3, CD34 and CD45RO in nasal mucosa and polyps from patients with chronic rhinosinusitis. Molecular Medicine Reports, 19 (4). doi: https://doi.org/10.3892/mmr.2019.9932 